\title{
A Disposable Copper (II) Ion Biosensor Based on Self-Assembly of L-Cysteine on Gold Nanoparticle-Modified Screen-Printed Carbon Electrode
}

\author{
Wong Pooi See, ${ }^{1}$ Sheila Nathan, ${ }^{1}$ and Lee Yook Heng ${ }^{1,2}$ \\ ${ }^{1}$ School of Chemical Sciences and Food Technology, Faculty of Science and Technology, Universiti Kebangsaan Malaysia (UKM), \\ 43600 Bangi, Selangor, Malaysia \\ ${ }^{2}$ South East Asia Disaster Prevention Research Institute (SEADPRI), Universiti Kebangsaan Malaysia, 43600 Bangi, Selangor, Malaysia
}

Correspondence should be addressed to Lee Yook Heng, leeyookheng@yahoo.co.uk

Received 26 May 2011; Accepted 4 October 2011

Academic Editor: Luca Francioso

Copyright (C) 2011 Wong Pooi See et al. This is an open access article distributed under the Creative Commons Attribution License, which permits unrestricted use, distribution, and reproduction in any medium, provided the original work is properly cited.

\begin{abstract}
A disposable copper (II) ion biosensor based on self-assembly of L-cysteine on gold nanoparticle-modified screen-printed carbon electrode was fabricated. The electrode was modified by attaching gold nanoparticles onto the surface of screen-printed carbon electrode through seed mediated growth method followed by self-assembly of L-cysteine. As demonstrated by differential pulse voltammetry, the sensor exhibited high sensitivity to copper (II) ion down to ppb (parts per billion) levels. Optimization of various experimental parameters such as $\mathrm{pH}$, buffer concentration, and preconcentration time, which influenced the performance of the biosensor, was investigated. The sensor demonstrated a wide linear response range from 10 to $0.005 \mathrm{ppm}(r=0.9870)$, with a lower detection limit of $8 \mathrm{ppb}$ using $10 \mathrm{~min}$ of preconcentration time. The sensor based on screen-printed electrode provides a cost-effective means of application of copper ion sensor for the detection of ppb level of copper ions in water.
\end{abstract}

\section{Introduction}

Copper as one of the essential trace elements in human's nutrition was being widely used in industrial and agricultural sectors. The extensive and excessive usage of copper in these areas has resulted in serious environmental contamination [1]. High level of copper in environment could lead to accumulation within the food chain [2]. High doses of copper in drinking water are hazard to human health. Thus, the urge to monitor copper content and toxicity in environment is highly desirable.

Most of the copper analyse are performed by conventional methods such as atomic absorption spectroscopy, inductively coupled plasma mass spectrometry, and inductively coupled plasma optical emission spectroscopy with solidphase extraction. Even though, these techniques are able to provide reliable and accurate results, but are time consuming and expensive, and require trained personnel for operation [3]. This has resulted in increasing demand in developing a more rapid, accurate, and reliable device for the detection of trace copper level for environmental monitoring [4]. The development of biosensors for the determination and quantification of metal ions in environmental monitoring is being actively explored.

The application of biosensors for quantitative analysis of metal ions offers accurate, sensitive, and fast respond on site measurement. Peptide- and oligopeptide-modified electrodes have been widely developed in recent years for the detection of metal ions in environmental samples due to their high affinities to different metal ions. Besides, by altering the sequence of amino acids within an oligopeptides, the affinities of the ligands to different metal ions can be tuned [57]. A number of peptide- and oligopeptide-based biosensors have been developed for the detection of copper ions. For instance, a Gly-Gly-His tripeptide-modified gold electrode showed high sensitivity and selectivity toward $\mathrm{Cu}^{2+}$ ions with low detection limit down to sub-ppt level $[6,8]$. An electrochemical biosensor based on polyaspartate modified gold electrode was able to determine copper ions concentrations down to $3 \mathrm{nM}$ [4]. Self-assembled monolayers of L-cysteine 
on gold electrode have been reported with a lower detection limit of less than $5 \mathrm{ppb}$ [3].

The majority of the metal sensors fabricated from peptides and oligopeptides on gold electrode suffered from major drawback such as non-cost effective in terms of mass production and commercialization. The application of screen printing electrode in the construction of versatile sensing devices allows fabrication of low-cost and simple sensors for in situ analysis. The potential of portability, simple instrumental design, and moderate cost have made screen-printed electrodes a primary choice in the construction of sensing devices $[8,9]$. On the other hand, the surface of screen-printed electrodes allows various chemical modifications for specific purposes. So far, only a disposal poly-L-histidine-modified screen-printed carbon electrode for detection of chromium (VI) has been developed by Bergamini et al. with a wide linear range and detection limit of $0.046 \mu \mathrm{M}$ [9].

Screen-printed electrodes modified with nanomaterials to enhance the sensitivity of sensing devices have been widely exploited. Among them, gold nanoparticles have been extensively used due to their unique properties such as a large surface area, good biocompatibility, and excellent catalytic and electronic property. A gold nanoparticlemodified carbon screen-printed electrode was constructed by Renedo and Martínez for the determination of antimony in seawater and pharmaceutical samples by using anodic stripping voltammetry demonstrated a detection limit of 9.4 pM [10]. Martínez-Paredes et al. have fabricated a goldnanostructured modified screen-printed carbon electrodes for the detection of lead by under-potential deposition of lead onto the nanostructure where the sensor exhibited a detection limit of $0.8 \mathrm{ng} / \mathrm{mL}$ [11]. Electrodeposition of gold nanoparticles onto the surface of carbon screen-printed electrode was being developed for determination of $\mathrm{Cr}$ (VI) using differential pulse voltammetry with a lower detection limit of $4.0 \times 10^{-7} \mathrm{M}$ by Renedo et al. [12]. However, there are very few literatures describing the self-assembly of amino acids, peptides, and oligopeptides onto gold nanoparticlemodified screen-printed carbon electrode for metal ions analysis.

The purpose of the present work is to investigate the performance of a disposal copper (II) ion biosensor based on self-assembly of L-cysteine on gold nanoparticle-modified screen-printed carbon electrode using differential pulse voltammetry. The significant of this work is on the modification of screen-printed carbon electrode with gold nanoparticles and self-assembly of L-cysteine onto the gold nanoparticles. This work presented a feasible way for constructing a cost effective, simple, and sensitive electrochemical device for metal ion analysis.

\section{Experimental}

Chemicals. Cetyltrimethylammonium bromide (CTAB), gold (III) chloride trihydrate $\left(\mathrm{HAuCl}_{4} \cdot 3 \mathrm{H}_{2} \mathrm{O}\right)$ and L-cysteine were purchased from Aldrich. Trisodium citrate dihydrate, ascorbic acid, sodium borohydride $\left(\mathrm{NaBH}_{4}\right)$, sodium hydroxide, ethanol, sodium acetate, acetate acid, sulfuric acid, potassium hydroxide, copper (II) nitrate, nickel (II) nitrate, and cobalt (II) were obtained from Sigma. All solutions were prepared by deionised water (Mili-Q, Milipore). Buffer solutions used in this work are $50 \mathrm{mM}$ acetate buffer $(\mathrm{pH}$ 6.0). The $\mathrm{pH}$ was adjusted with either $\mathrm{NaOH}$ or $\mathrm{HNO}_{3}$ solutions. Stock solution of copper (II) nitrate, nickel (II) nitrate, cobalt (II) nitrate, lead (II) nitrate, aluminium chloride, and zinc (II) nitrate $(0.1 \mathrm{M})$ was prepared in acetate buffer solution. Glassware was rinsed with $6 \mathrm{M} \mathrm{HNO}_{3}$ and then thoroughly rinsed by deionised water to avoid metal contamination.

Gold nanoparticles were deposited onto a screen-printed carbon electrode surface according to the methods described $[13,14]$ with slight modification. In brief, the screen-printed carbon electrode was immersed in a $0.01 \mathrm{M}$ of gold seed solution, which was prepared by mixing $0.5 \mathrm{~mL}$ of $0.01 \mathrm{M}$ $\mathrm{HAuCl}_{4}, 0.5 \mathrm{~mL}$ of $0.01 \mathrm{M}$ trisodium citrate dehydrate, and $18 \mathrm{~mL}$ of deionised water. After two hours of immersion, the screen-printed carbon electrode was removed from the gold seed solution and rinsed with deionised water and then dried with nitrogen gas before soaking in gold growth solution for 24 hours. The gold growth solution was prepared by adding in $0.5 \mathrm{~mL} 0.01 \mathrm{M} \mathrm{HAuCl}_{4}, 0.1 \mathrm{M}$ ascorbic acid, and $0.1 \mathrm{~mL}$ of $0.1 \mathrm{M} \mathrm{NaOH}$ into $18 \mathrm{~mL} 0.1 \mathrm{M}$ of CTAB. Self-assembly of L-cysteine on gold nanoparticle-modified screen-printed carbon electrode was performed as outlined in Scheme 1. The gold nanoparticle-modified electrodes were incubated in $75 \%$ ethanol, $25 \%$ water containing $10 \mathrm{mM}$ of $\mathrm{L}$-cysteine for 15 hours followed by rinsing with deionised water.

Electrochemical measurements in connection with cyclic voltmmetry and differential pulse voltammetry were performed using AUTOLAB PG12 (AUT 71681) Potentiostat/Galvanostat in a conventional three-electrode electrochemical cell comprising of a working electrode; in this case the gold nanoparticle-modified screen-printed carbon electrode and gold nanoparticles-L-cysteine-modified screen-printed carbon electrode, a glassy carbon electrode as auxiliary electrode, and a $\mathrm{Ag} / \mathrm{AgCl}$ electrode saturated with $\mathrm{KCl}$ were used as a reference electrode. The electrochemical characterization of gold nanoparticle-modified screen-printed carbon electrode was carried out at room temperature and $5 \mathrm{~mL}$ of $0.5 \mathrm{M}$ of $\mathrm{H}_{2} \mathrm{SO}_{4}$ was used as the carrier solution. For the investigation of electrochemical behavior of gold nanoparticles-L-cysteine-modified screenprinted carbon electrode, copper ions were accumulated at the modified electrode at a fixed potential by immersing the electrode in $10 \mathrm{~mL}$ of a stirred aqueous solution of copper (II) nitrate in $50 \mathrm{mM}$ acetate buffer ( $\mathrm{pH} \mathrm{4.5)}$ for $10 \mathrm{~min}$. The electrode was then removed from the mixture and rinsed with deionised water followed by transferring to a solution containing $50 \mathrm{mM}$ acetate buffer and $50 \mathrm{mM} \mathrm{NaCl}$ for electrochemical measurements.

The specificity of L-cysteine gold nanoparticle-modified screen-printed carbon electrode to $\mathrm{Cu}^{2+}$ was studied by adding some interferent metal ions into $2 \mathrm{ppm} \mathrm{Cu}^{2+}$ solution. A molar ratio of $0.04: 1$ of interferents to $\mathrm{Cu}^{2+}$ was chosen based on WHO guidelines for drinking water, where the interferent metal ions included in the investigation were $\mathrm{Ni}^{2+}, \mathrm{Co}^{2+}, \mathrm{Al}^{3+}, \mathrm{Zn}^{2+}$, and $\mathrm{Pb}^{2+}$. 


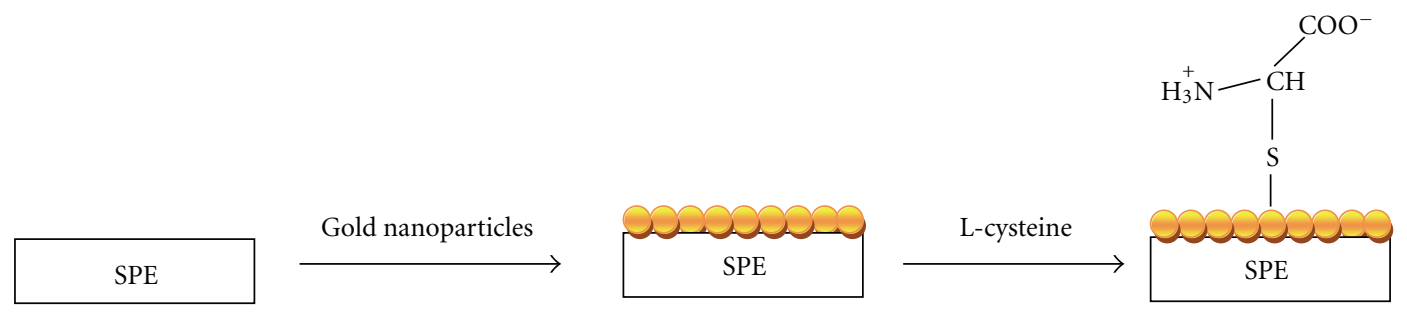

Scheme 1: Fabrication screen-printed carbon electrode modified with L-cysteine self-assembled on gold nanoparticles.

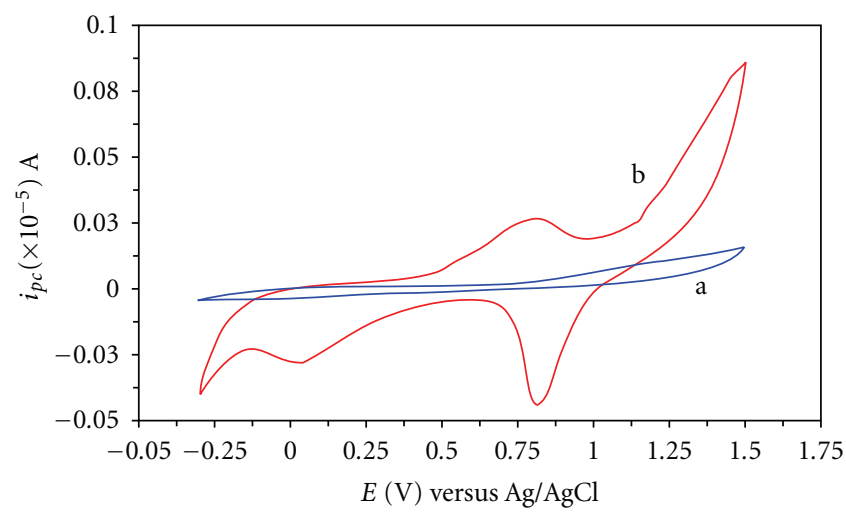

FIGURE 1: The cyclic voltammograms of a (a) bare screen-printed carbon electrode and (b) gold nanoparticles-modified screen-printed carbon electrode.

\section{Results and Discussion}

The cyclic voltammetry responses of the gold nanoparticlemodified screen-printed carbon electrode by seed-mediated growth method along with a bare screen-printed carbon electrode in $0.5 \mathrm{M} \mathrm{H}_{2} \mathrm{SO}_{4}$ solution are shown in Figure 1. The gold nanoparticle-modified screen-printed carbon electrode showed a well-defined symmetrical gold oxidation and reduction peaks at $0.76 \mathrm{~V}$. This observation confirmed that gold nanoparticles have been successfully attached onto the surface of the screen-printed carbon electrode. A shift in the gold oxide reduction potential of the deposited gold nanoparticles compared to planar gold at $0.98 \mathrm{~V}$ might be attributed to the attachment of gold nanoparticles on the carbon paste surface instead of gold surface. In addition, the peak area of the reduction of gold oxide suggested that a large amount of gold nanoparticles have been deposited onto the surface of the screen-printed carbon electrode. This can be confirmed by calculating the working areas of the gold nanoparticle-modified screenprinted carbon electrodes from the gold oxide reduction peak based on the amount of charge passed and using a factor of $482 \mu \mathrm{C} \mathrm{cm}^{-2}$ [15-17]. The calculated working area of the gold nanoparticle-modified screen-printed carbon electrode was $0.125 \mathrm{~cm}^{2}$ with a roughness factor of 0.11 . TEM measurements showed that the gold nanoparticle deposited on the screen-printed electrode had size ranged from 4 to $8 \mathrm{~nm}$ and these particles were distributed evenly on the nonuniform surface of the screen-printed electrode.
The differential pulse voltammogram of an L-cysteine gold nanoparticle-modified screen-printed carbon electrode measured in $50 \mathrm{mM}$ acetate buffer solution containing $50 \mathrm{mM} \mathrm{NaCl}$ is shown in Figure 2. In the absence of $10 \mathrm{ppm}$ $\mathrm{Cu}^{2+}$, a low background analytical signal was observed between $-0.40 \mathrm{~V}$ and $+0.60 \mathrm{~V}$. There was an increase in cathodic current after an accumulation of $\mathrm{Cu}^{2+}$. The increase was attributed to the reduction of $\mathrm{Cu}^{2+}$ to $\mathrm{Cu}^{+}$due to the binding of $\mathrm{Cu}^{2+}$ to $\mathrm{L}$-cysteine. It was proposed that $\mathrm{Cu}^{2+}$ coordinated with both the acidic $(-\mathrm{COOH})$ and basic $\left(-\mathrm{NH}_{2}\right)$ side groups of the amino acid $[3,18]$ with a ratio of $2: 1$ of cysteine to $\mathrm{Cu}^{2+}$ [3]. The effect of the amount of $\mathrm{L}-$ cysteine self-assembled onto the gold nanoparticle-modified screen-printed carbon electrode was evaluated with different concentrations of L-cysteine self-assembled onto the surface of the nanomaterial where the current response started to increase from 5 to $30 \mathrm{mM}$ of L-cysteine and became constant at higher concentrations (Figure 3). This suggests that the surface of the gold nanoparticles was fully self-assembled with L-cysteine molecules at $30 \mathrm{mM}$ concentration of Lcysteine.

The influence of $\mathrm{pH}$ on the complexation of $\mathrm{Cu}^{2+}$ with cysteine can be seen in Figure 4 where the optimum $\mathrm{pH}$ for the binding of $\mathrm{Cu}^{2+}$ to L-cysteine occurred at $\mathrm{pH} 6.5$, which was near to the isoelectric point (5.02) of L-cysteine. At this point, the L-cysteine exists as a zwitterion where the deprotonation of acidic and protonation of basic sides chain occur to allow the complexation of $\mathrm{Cu}^{2+}$ [19]. At $\mathrm{pH}$ lower than 2, the ionic property of the carboxylate side group $\left(\mathrm{p} K_{a}=1.88\right)$ will be lost because of the protonation of the acidic side group [18-20]. Similarly, at $\mathrm{pH}$ higher than 7, the basic amino side $\left(\mathrm{p} K_{a}=8.15\right)$ group will be deprotonated and loses its capability in coordinating with $\mathrm{Cu}^{2+}[18-20]$.

The effect of preconcentration time of $\mathrm{Cu}^{2+}$ on the electrochemical response of L-cysteine and gold nanoparticlemodified screen-printed carbon electrode was also investigated. As demonstrated in Figure 5, the cathodic current increases with increasing accumulation time and reaches constant pattern at $10 \mathrm{~min}$. Therefore, the preconcentration time of 10 min was chosen for further analysis.

The specificity of the modified screen-printed carbon electrode was assessed based on WHO guidelines [21] for drinking water, where the maximum level of copper in drinking water is $2 \mathrm{ppm}$ and interferents are allowed in the range of $0.01-0.07 \mathrm{ppm}$. Nickel and cobalt ions were chosen as part of the assessment since both of these metals exhibit 


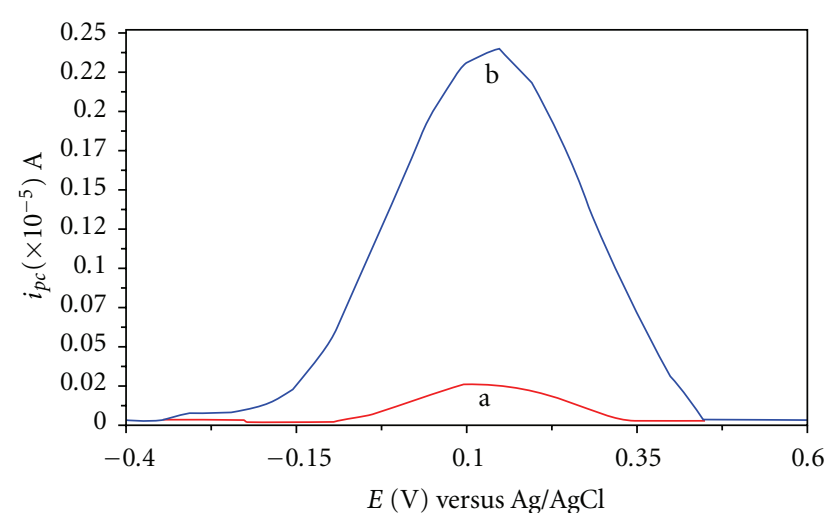

FIGURE 2: The current response of a screen-printed carbon electrode modified with L-cysteine and gold nanoparticles for the detection of $\mathrm{Cu}^{2+}$ in $50 \mathrm{mM}$ acetate buffer solution ( $\mathrm{pH}$ 6.5). (a) Before accumulation and (b) after accumulation of $10 \mathrm{ppm} \mathrm{Cu}^{2+}$ for $10 \mathrm{~min}$.

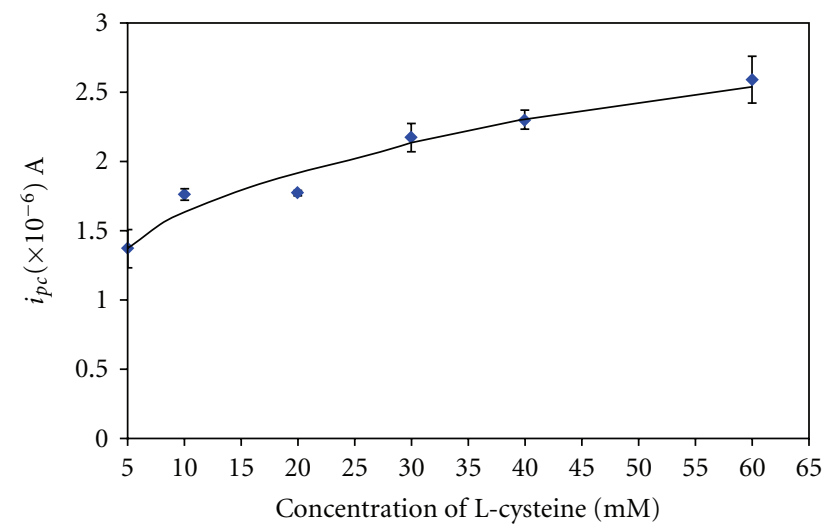

Figure 3: The effect of the amount of L-cysteine self-assembled onto the surface of gold nanoparticles on the response of modified screen-printed carbon electrode.

similar electrochemistry to $\mathrm{Cu}^{2+}$. The presence of $0.07 \mathrm{ppm}$ of $\mathrm{Co}^{2+}$ and $\mathrm{Pb}^{2+}$ exhibited observable interference, where more than $30 \%$ of the peak current differences were recorded when these ions were present together with $\mathrm{Cu}^{2+} \cdot \mathrm{Co}^{2+}$ showed strong interference since its ionic size is similar to $\mathrm{Cu}^{2+}$. The addition of maximum level $(0.07 \mathrm{ppm})$ of $\mathrm{Ni}^{2+}$, $\mathrm{Al}^{3+}$, and $\mathrm{Zn}^{2+}$ showed lesser interference. Table 1 displays the interference behavior of $\mathrm{Ni}^{2+}, \mathrm{Co}^{2+}, \mathrm{Al}^{3+}, \mathrm{Zn}^{2+}$, and $\mathrm{Pb}^{2+}$ on the cathodic current measured.

The modified screen-printed carbon electrode also exhibited a wide linear response range between 0.005 and $10 \mathrm{ppm}$ of $\mathrm{Cu}^{2+}$ with a correlation coefficient of 0.9870 and detection limit of $8 \mathrm{ppb}$ (Figure 6). The detection limit is far below the maximum limit of WHO [21] and EU [22] standards for copper in drinking water (2 ppm). The advantage of the screen-printed carbon electrode modified with L-cysteine self-assembled on gold nanoparticles over the other types of sensors for similar applications is the possibility of low-cost production and good sensitivity of the sensor reported here.

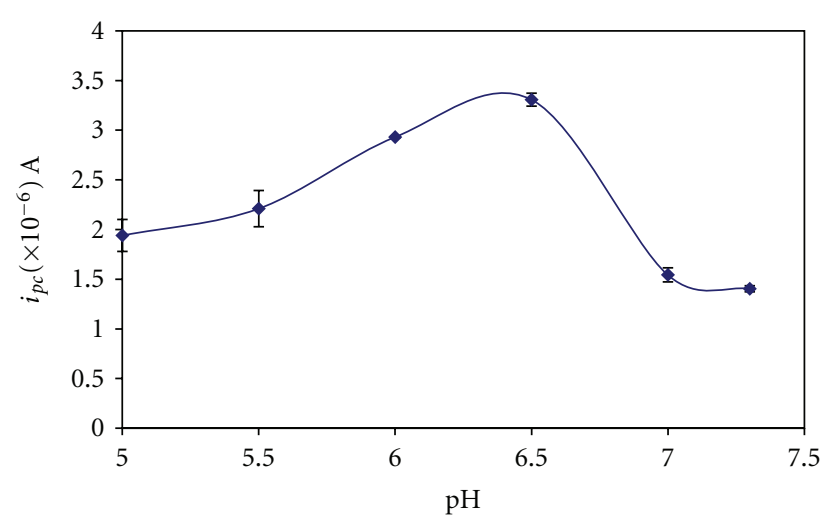

FIGURE 4: The effect of the pH (acetate buffer) on the response of the modified screen-printed carbon electrode during $\mathrm{Cu}^{2+}$ determination after $10 \mathrm{~min}$ of preconcentration time.

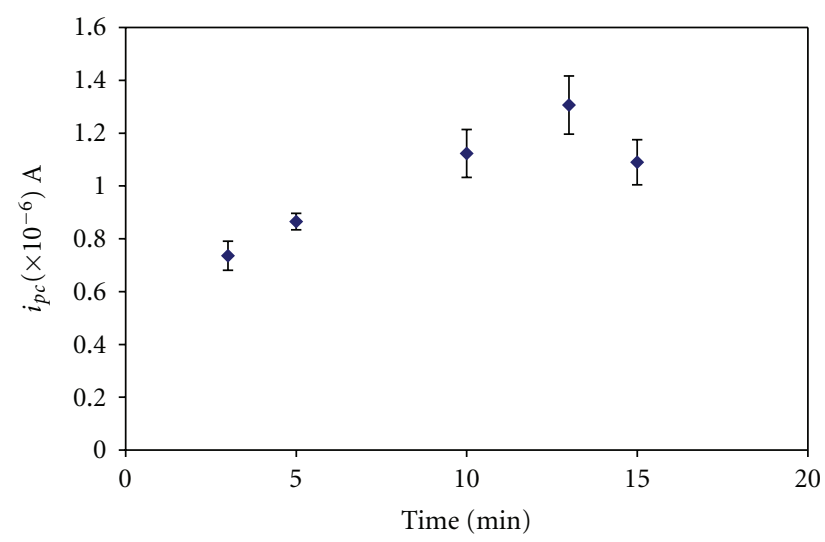

FIGURE 5: The current responses of a modified screen-printed carbon electrode after various accumulation times in $10 \mathrm{ppm} \mathrm{Cu}^{2+}$ (50 mM acetate buffer solution, $\mathrm{pH} 6.5$ ).

TABLE 1: Interference of various metal ions on the response of $\mathrm{Cu}^{2+}$ sensor based on L-cysteine assembled on gold nanoparticles of a modified screen-printed carbon electrode.

\begin{tabular}{lcc}
\hline Ion & Peak current $(\mu \mathrm{A})$ & $\begin{array}{c}\text { Current differences in the } \\
\text { presence of } 2 \mathrm{ppm} \mathrm{Cu} \mathrm{Cu}^{2+}(\%)\end{array}$ \\
\hline $\mathrm{Co}^{2+}$ & 1.11 & 38.99 \\
$\mathrm{Ni}^{2+}$ & 0.23 & 6.61 \\
$\mathrm{Zn}^{2+}$ & 0.45 & 13.65 \\
$\mathrm{~Pb}^{2+}$ & 1.11 & 38.99 \\
$\mathrm{Al}^{3+}$ & 0.66 & 18.60 \\
\hline
\end{tabular}

\section{Conclusion}

The use of modified carbon paste screen-printed electrode for a copper (II) ion sensor has been successful. The modification of screen-printed electrode by depositing gold nanoparticles with a seed-mediated growth method and self-assembling of L-cysteine onto the surface of the gold nanoparticles has yielded a sensor that demonstrated a wide linear response range to copper (II) ions between 0.005 and $10 \mathrm{ppm}$ and a detection limit of $8 \mathrm{ppb}$, which is low enough 


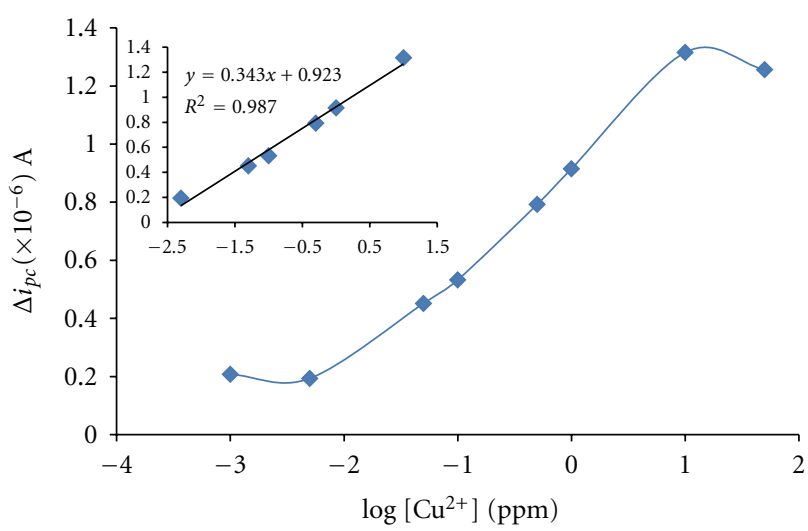

FIGURE 6: The response current of a screen-printed carbon electrode modified with L-cysteine assembled on gold nanoparticles to different copper ion concentrations. Inset: the linear response range of the sensor.

for drinking water analysis. These results demonstrated the potential of the modified screen-printed carbon electrode for cost effective electrode production and on site analysis of copper (II) ions in treated drinking water sources.

\section{Acknowledgments}

The authors acknowledge financial support from the Universiti Kebangsaan Malaysia via the Operational Research University Grant (UKM-OUP-NBT-29-151/2011) and the grant UKM-INDUSTRI-HEJIM-12-2010.

\section{References}

[1] H. Zhao, C. Xue, T. Nan et al., "Detection of copper ions using microcantilever immunosensors and enzyme-linked immunosorbent assay," Analytica Chimica Acta, vol. 676, no. 1-2, pp. 81-86, 2010.

[2] R. S. Freire and L. T. Kubota, "Application of self-assembled monolayer-based electrode for voltammetric determination of copper," Electrochimica Acta, vol. 49, no. 22-23, pp. 3795-3800, 2004.

[3] W. Yang, J. J. Gooding, and D. B. Hibbert, "Characterisation of gold electrodes modified with self-assembled monolayers of L-cysteine for the adsorptive stripping analysis of copper," Journal of Electroanalytical Chemistry, vol. 516, no. 1-2, pp. 10$16,2001$.

[4] W. Yang, J. J. Gooding, and D. B. Hibbert, "Redox voltammetry of sub-parts per billion levels of $\mathrm{Cu}^{2+}$ at polyaspartatemodified gold electrodes," Analyst, vol. 126, no. 9, pp. 15731577, 2001.

[5] W. Yang, E. Chow, G. D. Willett, D. B. Hibbert, and J. J. Gooding, "Exploring the use of the tripeptide Gly-Gly-His as a selective recognition element for the fabrication of electrochemical copper sensors," Analyst, vol. 128, no. 6, pp. 712-718, 2003.

[6] E. Chow, E. L. S. Wong, T. Böcking, Q. T. Nguyen, D. B. Hibbert, and J. J. Gooding, "Analytical performance and characterization of MPA-Gly-Gly-His modified sensors," Sensors and Actuators B, vol. 111-112, pp. 540-548, 2005.
[7] W. Yang, D. Jaramillo, J. J. Gooding et al., "Sub-ppt detection limits for copper ions with Gly-Gly-his modified electrodes," Chemical Communications, no. 19, pp. 1982-1983, 2001.

[8] M. Chikae, K. Idegami, K. Kerman et al., "Direct fabrication of catalytic metal nanoparticles onto the surface of a screenprinted carbon electrode," Electrochemistry Communications, vol. 8, no. 8, pp. 1375-1380, 2006.

[9] M. F. Bergamini, D. P. dos Santos, and M. V. B. Zanoni, "Development of a voltammetric sensor for chromium(VI) determination in wastewater sample," Sensors and Actuators B, vol. 123, no. 2, pp. 902-908, 2007.

[10] O. D. Renedo and M. J. A. Martínez, "Anodic stripping voltammetry of antimony using gold nanoparticle-modified carbon screen-printed electrodes," Analytica Chimica Acta, vol. 589, no. 2, pp. 255-260, 2007.

[11] G. Martínez-Paredes, M. B. González-García, and A. CostaGarcía, "In situ electrochemical generation of gold nanostructured screen-printed carbon electrodes. Application to the detection of lead underpotential deposition," Electrochimica Acta, vol. 54, no. 21, pp. 4801-4808, 2009.

[12] O. D. Renedo, L. Ruiz-Espelt, N. García-Astorgano, and M. J. A. Martínez, "Electrochemical determination of chromium(VI) using metallic nanoparticle-modified carbon screenprinted electrodes," Talanta, vol. 76, no. 4, pp. 854-858, 2008.

[13] J. Zhang and M. Oyama, "Electrocatalytic activity of threedimensional monolayer of 3-mercaptopropionic acid assembled on gold nanoparticle arrays," Electrochemistry Communications, vol. 9, no. 3, pp. 459-464, 2007.

[14] A. A. Umar and M. Oyama, "A cast seed-mediated growth method for preparing gold nanoparticle-attached indium tin oxide surfaces," Applied Surface Science, vol. 253, no. 4, pp. 2196-2202, 2006.

[15] J. C. Hoogvliet, M. Dijksma, B. Kamp, and W. P. van Bennekom, "Electrochemical pretreatment of polycrystalline gold electrodes to produce a reproducible surface roughness for self-assembly: a study in phosphate buffer $\mathrm{pH}$ 7.4," Analytical Chemistry, vol. 72, no. 9, pp. 2016-2021, 2000.

[16] W. H. Mulder, J. J. Calvente, and R. Andreu, "A kinetic model for the reductive desorption of self-assembled thiol monolayers," Langmuir, vol. 17, no. 11, pp. 3273-3280, 2001.

[17] K. Arihara, T. Ariga, N. Takashima et al., "Multiple voltammetric waves for reductive desorption of cysteine and 4mercaptobenzoic acid monolayers self-assembled on gold substrates," Physical Chemistry Chemical Physics, vol. 5, no. 17, pp. 3758-3761, 2003.

[18] J. J. Gooding, J. Shein, and L. M. H. Lai, "Using nanoparticle aggregation to give an ultrasensitive amperometric metal ion sensor," Electrochemistry Communications, vol. 11, no. 10, pp. 2015-2018, 2009.

[19] A. E. Martell and R. M. Smith, Critical Stability Constants, vol. 1 of Amino Acids, Plenum Press, New York, NY, USA, 1974.

[20] Y. Cui and C. Yang, "Electrochemical determination of copper (II) based on three-dimensional L-cysteine monolayer assembled on gold nanoparticles," in Proceedings of the $3 \mathrm{rd}$ International Conference on Bioinformatics and Biomedical Engineering (ICBBE'09), June 2009.

[21] Guidelines for Drinking-Water Quality, vol. 1, World Health Organization, 2008.

[22] European Standards for Drinking Water, World Health Organization, 2nd edition, 1970. 

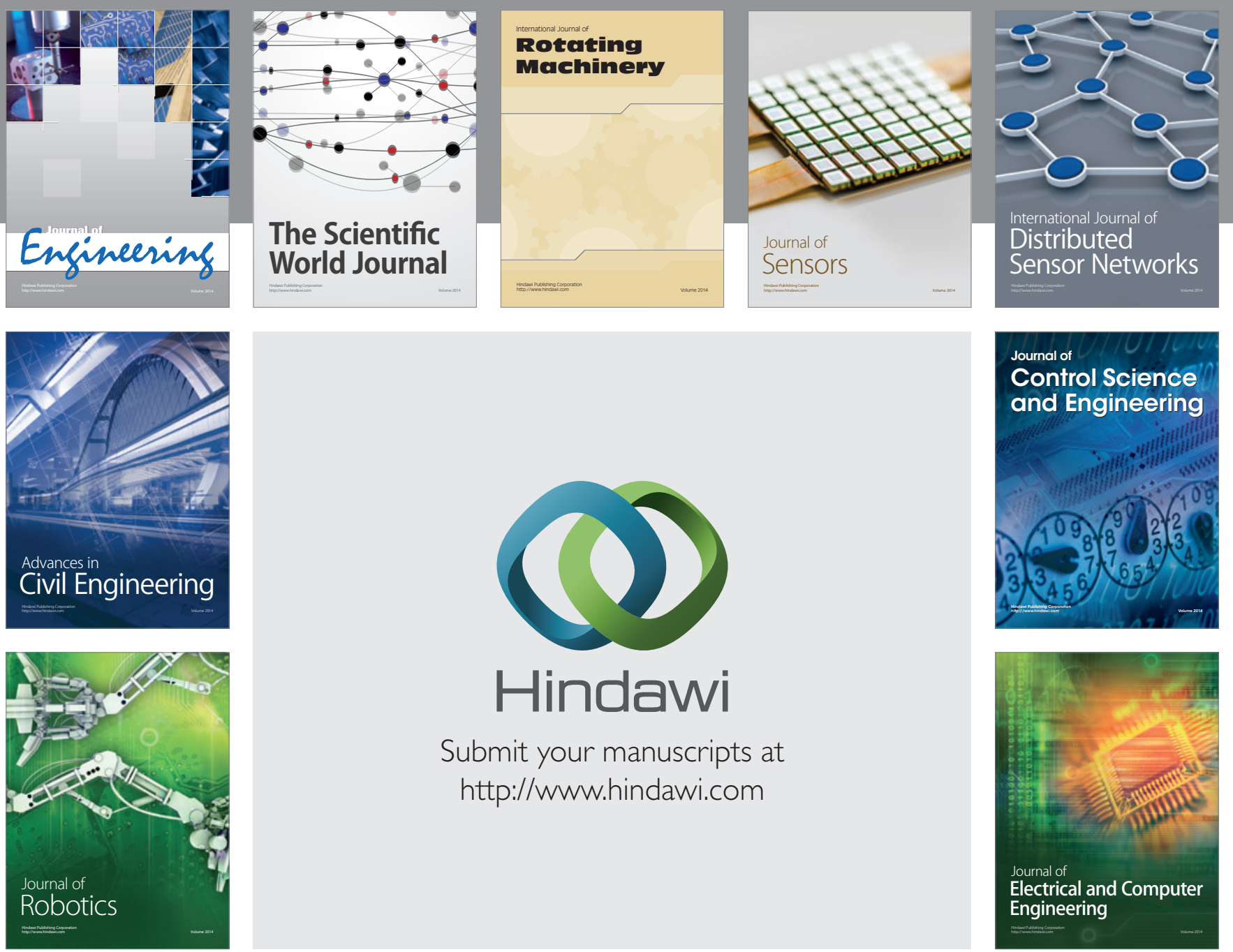

Submit your manuscripts at

http://www.hindawi.com
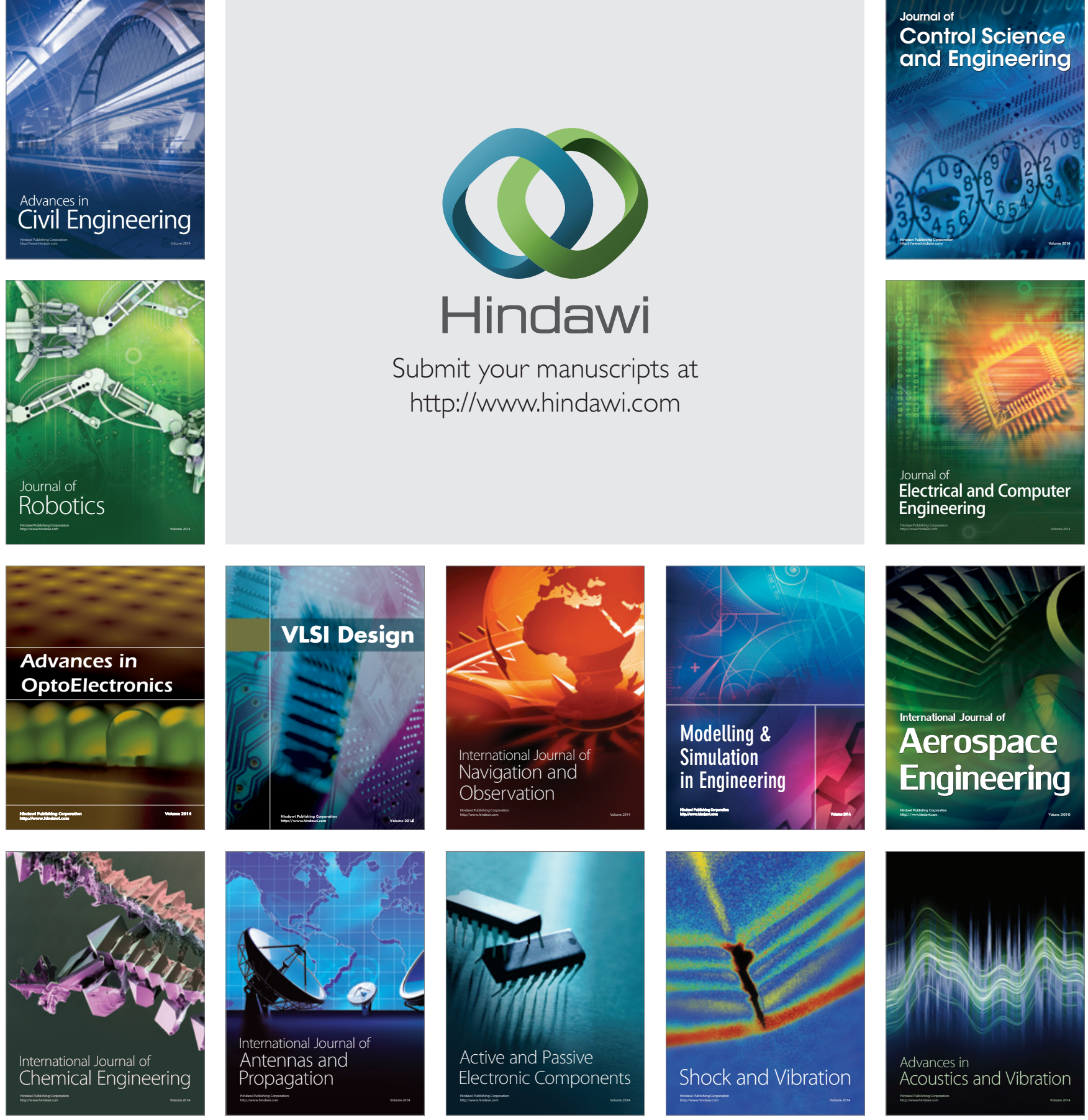